\title{
The Influence of Extension Professional's Job Satisfaction and the Quality of Relationship with Department Heads on Field Faculty Career Commitment to Montana State University Extension
}

\author{
S. Siegelin ${ }^{1}$, D. Lee ${ }^{2}$, C. Stone ${ }^{3}$
}

\begin{abstract}
This research increased the understanding of Extension professionals' career commitment by measuring the relationship between their job satisfaction and how they perceive their relationship with their supervisor using the Leader-Member Exchange Theory (LMX 7) and their career commitment. Montana State University Extension (MSUE) experiences periods of higher turnover among field-based professionals. The reasons for leaving are not well understood. Herzberg et al. (1959) identified intrinsic job satisfaction as a motivation factor and the extrinsic relationships with supervisors as one factor that influences employee dissatisfaction (Strong \& Harder, 2009). Thirty-six early career Extension professionals at MSUE were surveyed regarding job satisfaction (Benge \& Harder, 2017; Smerek \& Peterson, 2007); LMX 7 (Graen \& Uhl-Bien,1995); and original questions designed to establish the career commitment of Extension professionals to MSUE. Pearson's $r$ was calculated for the job satisfaction and LMX 7 scores with career commitment (the predicted percent of career worked for Extension). The research found a strong positive correlation between job satisfaction and career commitment $(r(22)=.76)$; and a weak positive correlation between LMX 7 and career commitment $(r(22)=.15)$. An additional question provided insights into the reasons why Extension professionals might leave their career.
\end{abstract}

\section{Keywords}

Leader-member exchange, LMX7, county agent, longevity, retention

1. Steven D. Siegelin, Director of Analysis, Planning, and Evaluation, Montana State University Extension, siegelin@montana.edu, (iD https://orcid.org/0000-0002-8239-9574

2. Daniel Lee, Associate Dean, Phyllis J. Washington College of Education, University of Montana, dan.lee@umontana.edu, (iD) https://orcid.org/0000-0003-4232-0363

3. Cody Stone, Executive Director, Montana State University Extension, cstone@montana.edu, 


\section{Introduction and Problem Statement}

In a 25-month period in 2016 to 2018, MSUE experienced and filled vacancies, representing $16 \%$ of the workforce. Extension professionals and administrators asked if there were systemic causes for this turnover. This research sought to understand how job satisfaction and supervisor relationships may influence early career turnover. Similar questions have been raised and observations made in past episodes of high turnover.

The sustained success and longevity of Extension professionals who are based in local communities through local government partnerships has been documented over the past 50 years (Arnold \& Place, 2010; Baker \& Hadley, 2014; Clegg, 1967; Forstadt \& Fortune, 2016; Fourman \& Jones, 1997; Harder et al., 2014; Hyatt, 1966; Lindner, 1998; Martin \& Kaufman, 2013; Morrill \& Morrill, 1967). Herzberg et al.'s (1959) Motivation-Hygiene theory identified that things unrelated to job responsibilities (hygiene factors) caused dissatisfaction that may result in a desire to separate. Smerek and Peterson (2007) developed a methodology to document employee satisfaction as a hygiene factor in non-extension university employees. Benge and Harder (2017) studied employee satisfaction and the Recommended Measure of LMX (LMX 7) instrument (Graen \& Uhl-Bien, 1995) to study the follower-leader relationship between Extension professionals in a county office with the County Extension Director (CED). This research sought to develop an understanding of the relationships between these two factors and Montana State University Extension (MSUE) professionals' career commitment to their positions.

Smerek and Peterson (2007) developed a conceptual model to study job satisfaction within the context of the Motivation-Hygiene Theory, "... which is comprised of (a) whether a job meets expectations, (b) is close to an ideal job, and (c) how satisfied a person is with their job" (Smerek \& Peterson, 2007, p. 234). Three survey prompts addressing these concepts were used by Benge and Harder (2017) in their research of local Extension professionals. This study adopted these three prompts to ascertain Extension professionals' satisfaction and how their responses related to career commitment to MSUE.

\section{Theoretical and Conceptual Framework}

The Motivation-Hygiene theory (Herzberg et al., 1959) identified the independent nature of job satisfaction and job dissatisfaction. They observed an absence of a directly related continuum from highly satisfied employees to highly dissatisfied employees. Instead, satisfaction and dissatisfaction are independent of each other (Smerek \& Peterson, 2007). The motivation factors drive satisfaction and are related to success in the job and other factors related to that success. Dissatisfiers, defined as hygiene issues, were influenced by routine factors not specifically related to the execution of work responsibilities, (Bruening \& Hoover, 1999; Herzberg et al., 1959) note that "when feelings of unhappiness were reported, they were not associated with the job itself but with conditions that surround the doing of the job" (Herzberg et al., 1959, p. 113). Motivation factors include achievement, recognition, work itself, 
responsibility, advancement, and growth. Hygiene factors include company policy and administration, supervision, relationship with supervisor, work conditions, salary, relationships with peers, personal life, relationships with subordinates, status, and security (Herzberg, et al., 1959). "In Herzberg's mind you could not improve job satisfaction by improving any of the 10 hygiene factors; you could only improve job satisfaction by increasing the six motivators" (Smerek \& Peterson, 2007, p. 231). Motivation factors are intrinsic in nature and hygiene factors are extrinsic. This research specifically studied the job satisfaction and the relationship with the supervisor and how they relate to career commitment.

Smerek and Peterson (2007) developed a conceptual model to study job satisfaction within the context of the Motivation-Hygiene Theory, "...which is comprised of (a) whether a job meets expectations, (b) is close to an ideal job, and (c) how satisfied a person is with their job" (Smerek \& Peterson, 2007, p. 234). Three survey prompts addressing these concepts were used by Benge and Harder (2017) in their research of local Extension professionals. This study adopted these three prompts to ascertain Extension professionals' satisfaction and how their responses related to career commitment to MSUE.

Benge and Harder (2017) explored LMX 7 scores of Extension professionals for their co-located County Extension Directors (CED). Their study included all Extension agents and explored LMX 7 results by years of service, program area, geographic region, educational level, years of the relationship, and gender. The LMX 7 survey instrument was developed over 25 years during the late twentieth century by Graen and Ulh-Bien (1995). It is a seven-item questionnaire using summated scale response options that measures the quality of the relationship between a follower and leader. In short, numeric scores for the responses are summed (range of 7 to 35 ) to establish the LMX 7 score. Graen and Uhl-Bien (1995) defined three qualitative descriptors based on the LMX 7 scores as the Stranger (LMX 7 score range of 7 to 19 points) relationship is highly contractual or transactional, Acquaintance (20 to 24 points) relationships have increasing social interactions with longer periods of reciprocation; it is a testing phase where they revert to the stranger phase or grow into the partner phase, and Partner (25 to 35 points) relationship includes in-kind support with undefined reciprocation that need not balance out in the end. Benge and Harder (2017) provided a detailed discussion of the descriptors and the theoretical framework for LMX 7 in the context of Extension professionals.

For the purpose of this study the following terms are defined.

- career commitment: The percent of predicted time to separation and to retirement.

- early-career extension professional: Agent with zero to five years with MSUE.

- job satisfaction: The quantitative measure of "whether a job meets expectations,... is close to an ideal job, and... how satisfied a person is with their job" (Smerek \& Peterson, 2007)

- LMX 7-stranger: "Interactions between the members occur on a more formal basis... relationship, exchanges are purely contractual: leaders provide... what [is needed] to perform, and followers... do only their prescribed job" (Graen \& Uhl-Bien, 1995, p. 230).

- LMX 7-acquaintance: "Increased social exchanges occur between the members... both on a personal and work level... and are part of a testing stage. There is still an equitable return of favor... within a limited time period" (Graen \& Uhl-Bien, 1995, p. 230). 
- LMX 7-partner: "Exchanges between the members are highly developed: they are exchanges "in kind" and may have a long time span of reciprocation.... The individuals can count on each other for loyalty and support" (Graen \& Uhl-Bien, 1995, p. 230).

\section{Purpose}

The purpose of this research was to explore how job satisfaction, and leader-member exchange related to career commitment to MSUE. To accomplish this purpose four research objectives guided this study:

- Quantify participant career commitment.

- Quantify participant job satisfaction and analyze its relationship with career commitment.

- Quantify participant leader-member exchange and analyze its relationship with career commitment.

- Document reasons participants think they might leave MSUE in the future.

\section{Methods}

This correlational study included data from MSUE county-based faculty (agents). Developing an understanding of the utility of the short and simple job satisfaction and LMX 7 instruments as easily implemented predictors of career commitment was of interest to leaders. The addition of four questions that established career commitment and attitudes related to job searching or dissatisfaction were developed to keep the questionnaire simple and easy to complete (13 fixed-response and one free-response questions). The study was deemed exempt from IRB review. An a priori acceptable correlation value of $r>.70$ or a strong positive correlation (Akoglu, 2018) was established. The target population for this study was county-based faculty serving in their first five years of service in the MSUE $(N=36)$. There was interest from MSUE Administration to better understand factors that may influence early career professionals to seek other employment. A census was attempted with a response rate of $67 \%(n=24)$. Due to incomplete questionnaires, the effective response rate in some correlations was as low as $58 \%$ $(n=21)$. This response rate for electronic surveys is similar to others administered to Extension professionals; 58\% (Brain et al., 2009), 62\% (Adams et al., 2009), 68\% (Benge \& Harder, 2017), and 69\% (Benge et al., 2011).

Data were collected in the spring of 2018 using a questionnaire that utilized previously developed questions for job satisfaction (Benge \& Harder, 2017; Smerek \& Peterson, 2007) and a modified LMX 7 (Benge \& Harder, 2017; Graen \&Uhl-Bien, 1995), and researcher developed questions to document predicted career commitment and reasons for leaving MSUE. Leadermember exchange, and career commitment, and predicted reasons for leaving data were presented in 2018 as a poster at the National Association of Extension Program and Staff Development Professionals Annual Meeting in Alexandria, VA.

This research had three limitations. The participants could misinterpret the questions and provide responses that are not consistent with the original intent. The reliability of the LMX 7 
instrument was noticeably lower than others have reported (discussed in the Findings and Conclusions, Discussions, and Recommendations). This research asked participants to predict future actions and reasoning. To address these limitations the questionnaire was vetted by independent researchers or administrators in agriculture education, education, or Extension in three states and four institutions. Consideration of these limitations should be given when applying of these results to other Extension systems.

All locally based extension professionals of MSUE hired between January 1, 2013 and February 28, 2018 served as the population for this research, names were provided by MSUE Human Resources. Faculty members who satisfied this delimitation ranged in age from mid-twenties to sixties. The majority of participants were female. All were Caucasian with some Hispanic representation.

The sum of the job satisfaction numeric equivalents, LMX 7 score and predicted percent of career spent with MSUE (a higher scores are better) were utilized to calculate Pearson's $r$ correlation coefficient to determine the strength and direction of the correlation (SPSS, versions 25 and 27). The dependent variable, career commitment, was calculated by taking the percentage of predicted times of service with MSUE and to retirement from all careers. This transformation was necessary because the population for this study included professionals at a variety of career and life stages which would have confounded the data if not adjusted for the number of years until final retirement. The independent and dependent variables are interval and ratio in character, respectively.

\section{Findings}

\section{Objective 1: Quantify participant career commitment}

Participants predicted how many years they thought they would work for MSUE and how many years they would work before retiring from all careers. A percentage was calculated and serves as the numeric representation of career commitment in this study. Seven participants $(n=21)$ predicted they will spend $\leq 20 \%$ of their career with MSUE; 12 participants predicted they will spend less than half their career with MSUE; nine participants predicted they would spend more than half their career with MSUE; and four would retire from MSUE, see Figure 1. 
Figure 1

Career Commitment of Early Career Extension Professionals to MSU Extension

Extension Professionals Prediction of Percentage of Career Served with MSU Extension (frequency of repsonses)

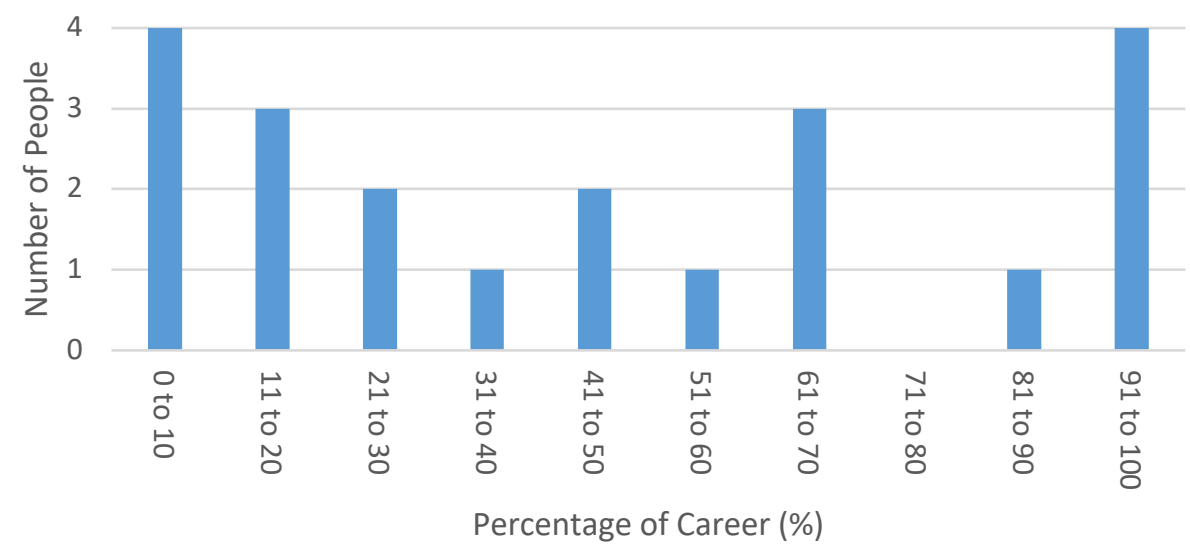

To further understand the commitment to Extension as a career of the participants a question was asked what their career intentions were with MSUE, see Table 1. Seventy-eight percent ( $n$ $=23$ ) of the participants indicate they are content or plan to retire in their current position. These results show that $21.7 \%(n=23)$ of the participants were predicting they would try to leave their position in the next few years.

\section{Table 1}

Career Intentions with MSUE

\begin{tabular}{lll}
\hline Survey Prompt & $f$ & $\%$ \\
\hline I am actively seeking employment outside MSUE & 0 & 0.0 \\
I hope to find a position outside MSUE in the next few & 5 & 21.74 \\
years & & \\
I am content in my current position & 14 & 60.87 \\
I plan to retire from MSUE & 4 & 17.39 \\
\hline
\end{tabular}

Objective 2: Quantify participant job satisfaction and analyze its relationship with career commitment

Table 2 and Figure 2 show the results to three questions in the survey instrument designed to measure Extension professionals' job satisfaction. All participants agreed that their current job matches their ideal job and over $90 \%(n=23)$ are satisfied with their jobs. However, when asked if their current job exceeds their expectations, agreement dropped to about $61 \%(n=23)$. Nearly $40 \%$ of participants $(n=23)$ disagreed that their current job exceeds their expectations. The correlation between career commitment and job satisfaction is shown in Figure 2. 


\section{Table 2}

Frequency of Reponses for Job Satisfaction and Expectations of Early Career Professionals in Cooperative Extension System

\begin{tabular}{lllll}
\hline & \multicolumn{4}{c}{$\%(n=23)$} \\
\cline { 2 - 5 } Survey prompt & SA & SWA & SWD & SD \\
\hline My current job matches my ideal job & 34.8 & 65.2 & 0.0 & 0.0 \\
I am satisfied with my job (Consider all the expectations you & 56.5 & 34.8 & 8.7 & 0.0 \\
had when you started your current job) & 26.1 & 34.8 & 34.8 & 4.4 \\
My current job exceeds those expectations & & &
\end{tabular}

Note. SA = Strong Agree, SWA = Somewhat Agree, SWD = Somewhat Disagree, SD =Strongly Disagree

Figure 2

Correlation of Percent of Career v. Job Satisfaction and Expectation Total Score

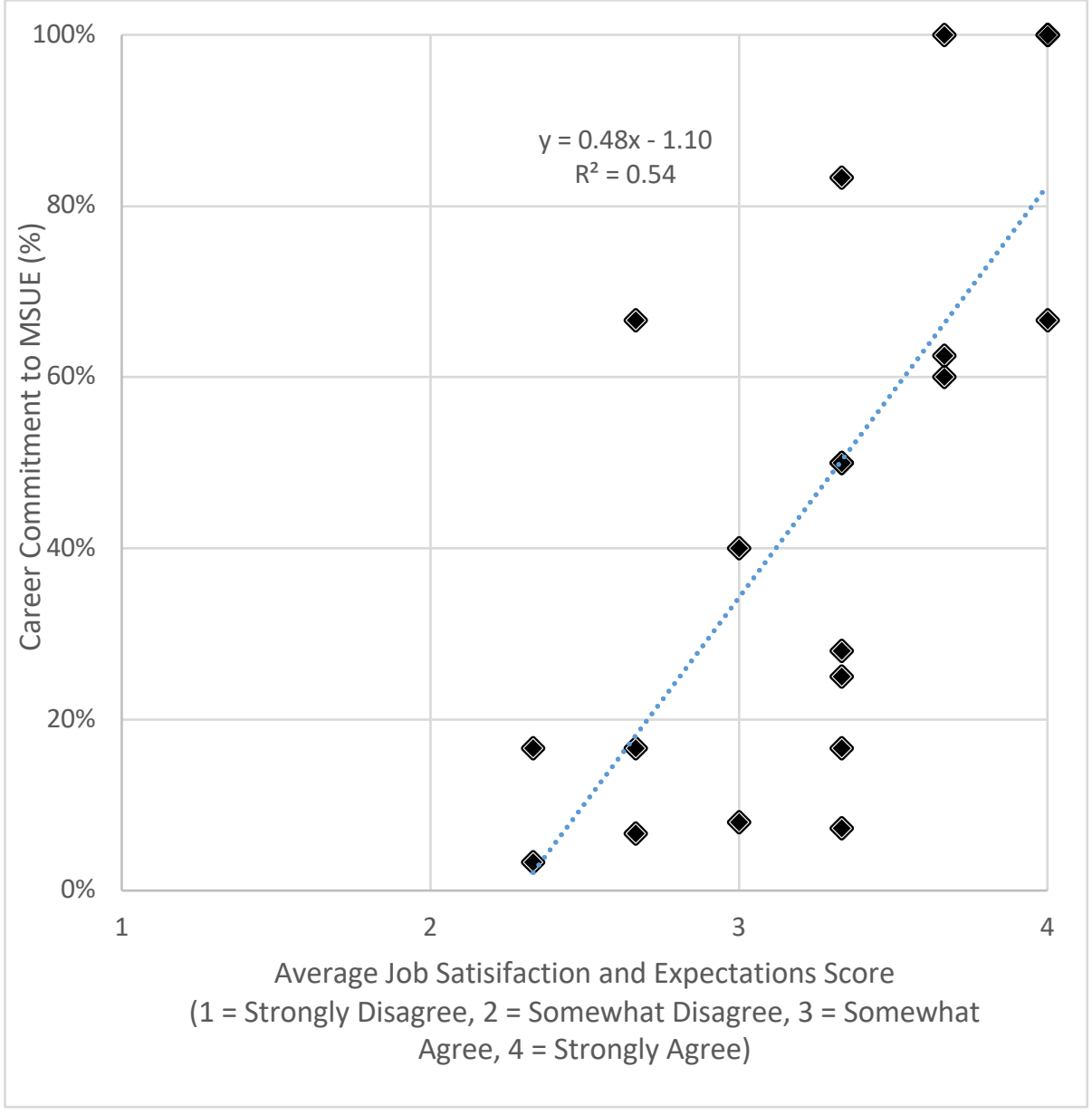


The correlation between career commitment and job satisfaction was strong positive $\left(r^{2}=.54\right)$, see Table 3. Cronbach's alpha was calculated to assess the reliability of the job satisfaction instrument ( $\alpha=.71$ ) (Chronbach, 1951).

Table 3

LMX 7 Results - Descriptive, Correlation, and Reliability Statistics

\begin{tabular}{llllll}
\hline Variable & $n$ & $M$ & SD & $r^{1}$ & $\rho^{1}$ \\
\hline Job Satisfaction and Expectations $^{2}$ & 23 & 5.3 & 1.7 & .76 & .77 \\
LMX 73 $^{3}$ & 23 & 19.5 & 3.5 & .15 & .24 \\
MSUE Career $(\%)^{4}$ & 22 & 45.8 & 35.3 & & \\
\hline
\end{tabular}

${ }^{1}$ Correlation coefficients. Spearman's rho shared for those who prefer a non-parametric analysis of Likert-scale data (Kero \& Lee, 2016). ${ }^{2}$ Scale: 1 = Strongly Disagree, 2 = Somewhat Disagree, 3 = Somewhat Agree, 4 = Strongly Agree. ${ }^{3}$ Scale: 7 to 35 with 35 being most positive using various Likert-scales (1-5). ${ }^{4}$ The percent of the respondent's career they intend to work for MSUE (calculated)

\section{Objective 3: Quantify participant leader-member exchange and analyze its relationship with career commitment}

The cumulative LMX 7 score for an individual could range from seven to 35 points. Those faculty with LMX scores of seven to 19 are described in the Stranger phase with their supervisor, 20 to 24 in the Acquaintance phase, and 25 to 35 in the Partner phase. The use of one qualitative question in the survey instrument provided avenues to better understand quantitative data in the research. Cronbach's alpha was calculated to assess the reliability of the LMX 7 instrument ( $\alpha=.46)$ (Chronbach, 1951).

A visual inspection of the scatter plot demonstrates that there is a weak positive relationship between the follower-leader relationship as measured by the LMX 7 and career commitment of MSUE early career professionals. Figure 3 shows that 14 respondents were in the stranger, seven were in the acquaintance, and two participants were partner phases. Four respondents indicated that they would spend one hundred percent of their career with MSUE. Three of these participants fell in the Stranger phase with scores of 19 and the fourth was in the Acquaintance phase with a score of 21. None of these participants with high career commitment to MSUE had Partner phase relationships with their supervisors. In contrast, the two participants who were in the Partner phase of relationship with their supervisor had career commitments of forty and seventeen percent. Eleven $(n=21)$ participants indicated that they would spend half or more of their career with MSUE. Ten participants indicated they would spend less than half of their career with MSUE. Eight indicated that they would spend less than one fourth of their career with MSUE. 


\section{Figure 3}

Correlation between Leader-Member Exchange Score v. Career Commitment to MSUE (\%), with Phase of Leadership Making (shaded areas)

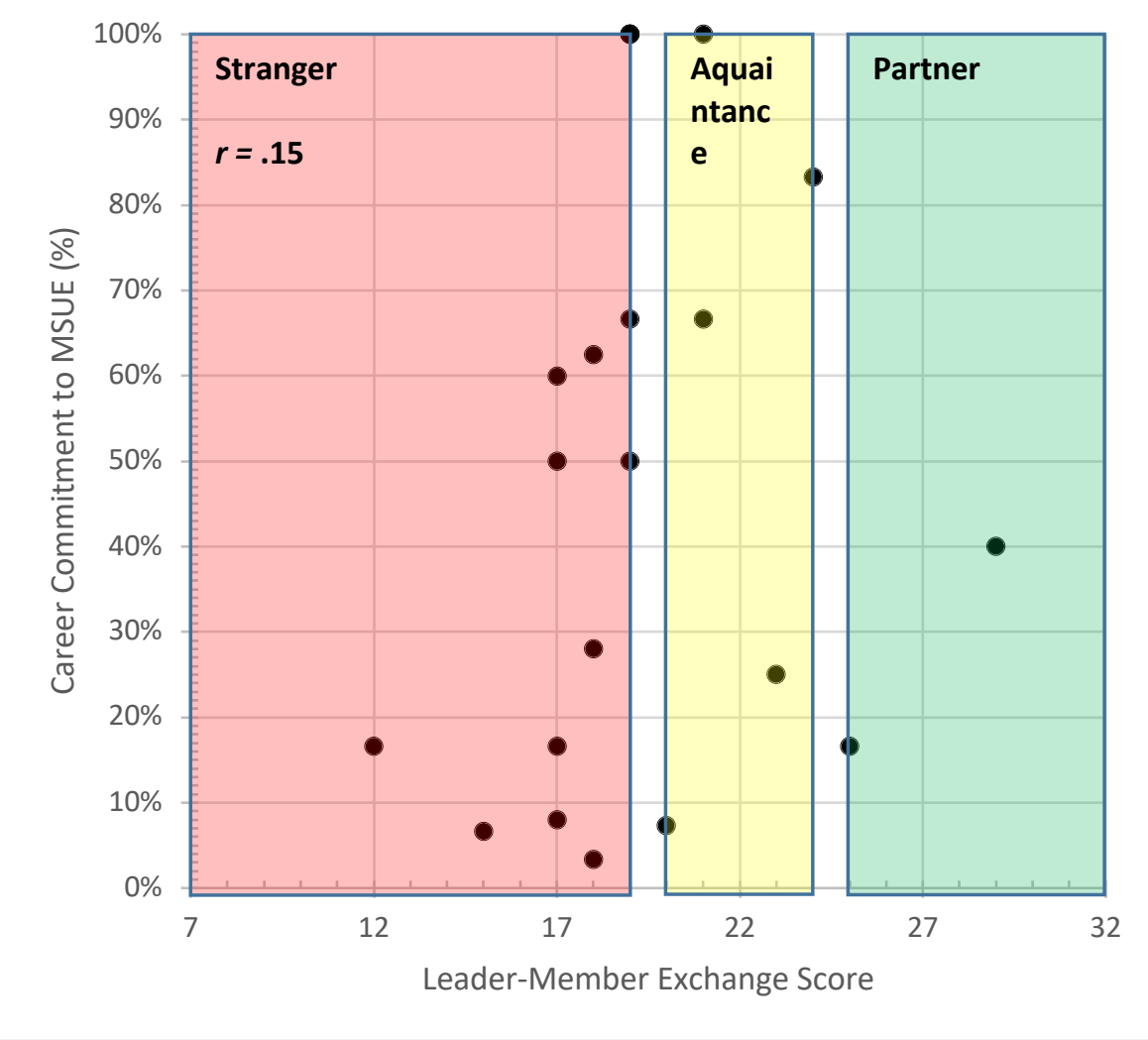

Objective 4: Document reasons participants think they might leave MSUE in the future Nineteen participants provided reasons why they might leave MSUE in the future. Participants responded to the following prompt, "To the best of your ability, please share the reason(s) you believe you will leave MSU Extension, whenever that may be". Responses were sorted into four emergent categories: Full career with MSUE, personal goals, professional goals, and hygiene factors. Lists that spanned two or more categories were included in all relevant categories. Ten responses (52.6\%) included personal goals. The most frequent themes within this category were related to family goals including children or starting a family, living closer to extended family, or moving to a place more suitable for the whole family. Professional goals included responses that demonstrated desires for career advancement. Some participants shared that they would like to "find a better job", have the "opportunity to explore new career avenues", obtain an advanced degree, have "a new focus... [or] experience", or "own/manage a ranch with my [spouse]". Hygiene factors included three participants mentioning concerns about organizational leadership; one specifically mentioned lack of support from their supervisor and the others referenced a lack of leadership in general terms. A dissatisfaction with level of pay (too low or a desire for higher pay) was also mentioned by three participants. Lack of growth in budgets was another concern shared. 


\section{Conclusions, Discussion, and Recommendations}

This research indicates that career-long commitment from Extension professionals may not be a realistic administrative goal. One fourth of the research population $(N=36)$ or $41 \%(n=22)$ or respondents indicated that they would spend less than 30\% of their career with MSUE. All 22 respondents indicated that their current job was their ideal job. Extension administrators and staff development professionals may need to consider how to orient, onboard, and train new faculty for rapid success to maximize the impacts the employee has for Extension in three to 10 years in a position.

A more successful strategy for retention may be to focus on enhancing the motivation factors that drive satisfaction (intrinsic motivators) and minimize dissatisfying hygiene factors (extrinsic motivators) that may increase willingness to pursue other employment. Often times orientation and onboarding training focuses much of the allotted time on policy and procedures, employment related issues (benefits, reporting or information systems, compliance issues important for getting paid, etc.). These items are hygiene issues that are important to organizational success but are not contributors to satisfaction or career commitment. Addressing both motivators and hygiene factors may increase or extend career commitment amongst professionals.

It is commendable that all participants agreed that their current job matched their ideal job. This indicates that MSUE's hiring and applicant filtering processes are identifying people who identify with the role of Extension professionals. Over $90 \%(n=23)$ of participants agreed that they were satisfied in their position. However, nearly $40 \%(n=23)$ participants disagreed that their job exceeded their expectations. This may allow MSUE to explore ways to help professionals identify reasonable expectations that meet or exceed their own expectations. MSUE may also be able to identify and address systemic assets, opportunities, or limitations to enhance professionals' intrinsic success that may increase career commitment.

The relationship between job satisfaction and career commitment was strong positive $(r(22)=$ .76) (Akoglu, 2018). The simple nature of the three questions used to develop MSUE professionals' job satisfaction and the strong positive correlation to career commitment could be a valuable measure of individual and collective attitudes and a predictor of likely future turnover. If these satisfaction questions were gathered in a confidential manner over time; MSUE could develop further understanding of job satisfaction across the organization. This could allow the tracking of individual and collective trends over years and further validate or refine the predictive utility of this relationship as individual responses and trends could be considered over time and when individuals leave the system. Career expectations that relate to hygiene factors could be of utmost importance to helping MSUE Administration develop strategies and practices that minimize the impact of hygiene issues that may increase dissatisfaction. 
The LMX 7 instrument's relationship with career commitment is weak positive $(r(22)=.15)$; however, this is not a negative result. The findings reveal that the relationship between the professional and the supervisor is not negatively impacting career commitment of early career professionals. These results indicate the role of the supervisor in early career turnover is not a major factor. The distribution of over $80 \%(n=24)$ of the respondents in the stranger or acquaintance phase of relationship building is interesting and deserves further exploration. This research explored a new application of the LMX 7 instrument in an Extension context. Benge and Harder (2017) studied the follower-leader relationship between Extension professionals at all stages of career with their co-located leader who was in regular contact with the follower. This research found lower LMX 7 scores for follower-leader relationships where they interact inperson on a limited basis ( 3 to 15 times per year). Benge and Harder's (2017) work found greater percentages of LMX 7 scores in the Partner phase. The population of their study included all extension professionals in local offices and studied the relationship with their colocated supervisor. The greater years of service in their research population and the increased interaction with the co-located supervisor may explain the differences. More research to understand the growth and limitations of leader-member exchange when supervisor interactions are limited by time and distance may be important for Extension systems to understand what is possible in such organizational structures.

The low reliability of the LMX 7 questionnaire in this research $(\alpha=.46)$ brings into question its utility in this application. The reliability of the LMX 7 scale was noticeably lower than those reported by previous researchers (Benge \& Harder, 2017; Gerstner \& Day, 1997; Maslyn \& UhlBien, 2001). Further analysis found that if LMX 7 questions one and two were eliminated, Cronbach's alpha rose to .71. Alternative correlations were calculated substituting the sum of LMX 7 questions three through seven to explore whether the problematic questions were influencing the results or data interpretation. Both Pearson's $r$ and Spearman's rho showed similar, yet lower correlation strength to the original analysis $(r(22)=.11$ and $\rho(22)=.13)$. As a result, the original LMX 7 score and correlation were discussed here.

This research results in several questions that deserve further consideration. Developing the longitudinal and predictive utility of the three job satisfaction questions to indicate individual and organizational career commitment over time could be valuable. Instead of hoping every new hire will spend their career in Extension; administrators could utilize longitudinal results to identify individuals in need of support, predict future vacancy rates, or identify rapid shifts in organizational morale. Research that gains a better understanding of what a realistic career commitment is for newly hired employees may help Extension leadership create a more satisfying and rewarding work environment. Finally, the LMX 7's low reliability scores in this study is concerning. Additional research of the LMX 7 instrument in non-co-located employees and supervisors could help validate or invalidate the instrument in these Extension employeesupervisor relationships. 


\section{References}

Adams, A. E., Place, N. T., \& Swisher, M. E. (2009). Knowledge levels regarding the concept of community food security among Florida Extension agents. Journal of Extension, 47(4). https://archives.joe.org/joe/2009august/rb2.php

Akoglu, H. (2018). User's guide to correlation coefficients. Turkish Journal of Emergency Medicine, 18(3), 91-93. https://doi.org/10.1016/i.tjem.2018.08.001

Arnold, S., \& Place, N. (2010). Influences of agriculture agents' decisions to remain in an Extension career. Journal of Agricultural Education, 51(2), 36-45. https://doi.org/10.5032/jae.2010.02036

Baker, L. M., \& Hadley, G. (2014). The new agent: A qualitative study to strategically adapt new agent professional delopment. Journal of Extension, 52(5). https://archives.joe.org/joe/2014october/a3.php

Benge, M., \& Harder, A. (2017). The effects of leader-member exchanges on the relationships between Extension agents and county extension directors in Florida. Journal of Human Sciences and Extension, 5(1), 35-49. https://www.jhseonline.com/article/view/631/547

Benge, M., Harder, A., \& Carter, H. (2011). Necessary pre-entry competencies as perceived by Florida Extension agents. Journal of Human Sciences and Extension, 5(1), 35-49. https://www.jhseonline.com/article/view/631/547

Brain, R. G., Irani, T. A., Hodges, A. W., \& Fuhrman, N. E. (2009). Agricultural and natural resources awareness programming: Barriers and benefits as perceived by county Extension agents. Journal of Extension, 47(2). https://archives.joe.org/joe/2009april/a3.php

Bruening, T. H., \& Hoover, T. S. (1990, November 30). Impact of personal life factors on the effectiveness and satisfaction of teachers [Conference Session]. National Agricultural Education Research Meeting: Focusing Agriculture Education Research: The Challenge of the 1990s \& Beyond, Cincinnati, OH, United States. https://files.eric.ed.gov/fulltext/ED336529.pdf

Chronbach, L. J. (1951). Coefficient alpha and the internal structure of tests. Psychometrika, 16(3), 297-334. https://doi.org/10.1007/BF02310555

Clegg, D. O. (1967). Motivation theory in practice. Journal of Extension, 5(1), 23-29. https://archives.joe.org/joe/1967spring/1967-1-a3.pdf 
Forstadt, L., \& Fortune, A. (2016). Personal sustainability: Listening to Extension staff and observing organizational culture. Journal of Extension, 54(2). https://tigerprints.clemson.edu/cgi/viewcontent.cgi?article=1973\&context=joe

Fourman, L. S., \& Jones, J. (1997). Job enrichment in Extension. Journal of Extension, 35(5). https://archives.joe.org/joe/1997october/iw1.php

Gerstner, C. R., \& Day, D. V. (1997). Meta-analytic review of leader-member exchange theory: Correlates and construct issues. Journal of Applied Psychology, 82(6), 827-844. https://doi.org/10.1007/s12144-018-0095-1

Graen, G. B., \& Uhl-Bien, M. (1995). Relationship-based approach to leadership: Development of leader-member exchange (LMX) theory of leadership over 25 years: Applying a multidomain perspective. The Leadership Quarterly, 6(2), 219-247. https://doi.org/10.1016/1048-9843(95)90036-5

Harder, A., Gouldthorpe, J., \& Goodwin, J. (2014). Why work for Extension? An examination of job satisfaction and motivation in a statewide employee retention study. Journal of Extension, 52(3). https://archives.joe.org/joe/2014june/a5.php

Herzberg, F., Mausner, B., \& Snyderman, B. B. (1959). Motivation to Work. Taylor and Francis Group. https://doi.org/10.4324/9781315124827

Hyatt, G., Jr. (1966). Staff competence. Journal of Extension, 4(3), 135-142. https://archives.joe.org/joe/1966fall/1966-3-a1.pdf

Kero, P., \& Lee, D. (2016). Likert is pronounced "LICK-urt" not "LIE-kurt" and the data are ordinal not interval. Journal of Applied Measurement, 17(4), 1-8. http://jampress.org/abst2016.htm

Lindner, J. R. (1998). Understanding employee motivation. Journal of Extension, 36(3). https://archives.joe.org/joe/1998june/rb3.php

Martin, M. J., \& Kaufman, E. K. (2013). Do job satisfaction and commitment to the organization matter when it comes to retaining employees? Journal of Extension, 51(4). https://archives.joe.org/joe/2013august/rb1.php

Maslyn, J. M., \& Uhl-Bien, M. (2001). Leader-member exchange and its dimensions: Effects of self-effort and other's effort on relationship quality. Journal of Applied Psychology, 86(4), 697-708. https://doi.org/10.1037/0021-9010.86.4.697

Morrill, J. G., \& Morrill, O. L. (1967). Personnel plateauing and motivation. Journal of Extension, 5(1), 15-22. https://archives.joe.org/joe/1967spring/1967-1-a2.pdf 
Smerek, R. E., \& Peterson, M. (2007). Examining Herzberg's theory: Improving job satisfaction among non-academic employees at a university. Research in Higher Education, 48(2), 229-250. https://doi.org/10.1007/s11162-006-9042-3

Strong, R., \& Harder, A. (2009). Implications of maintenance and motivation factors on Extension agent turnover. Journal of Extension, 47(1). https://archives.joe.org/joe/2009february/a2.php

(C) 2021 by authors. This article is an open access article distributed under the terms and conditions of the Creative Commons Attribution license (http://creativecommons.org/licenses/by/4.0/). 